\title{
Cultural Politics and Political Culture of Web 2.0 in Asia
}

\author{
David Kurt Herold
}

Received: 21 February 2009/Accepted: 2 March 2009/Published online: 19 March 2009

(C) Springer Science + Business Media B.V. 2009

The articles in this special issue are concerned with the effects of the internet and more specifically of the tools, practices, and skills collectively known as "Web 2.0" on Asian societies and cultures and are based on presentations given by the authors at the conference "The Role of New Technologies in Global Societies" held July 30-31, 2008 at the Hong Kong Polytechnic University. They collectively and individually argue that instead of employing a crude technological determinism, it might be more useful to study the myriad ways in which both the internet and local cultures influence each other and contribute to the creation of new forms of techno-cultures and technosocieties.

The 'Western' origins of the internet and of Web 2.0 and their embeddedness in 'Western' cultural practices have led many in the mass media to the assumption that the adoption of the internet and of the 'democratic' practices of Web 2.0 would hasten the transformation of Asian societies along European and North-American lines (see e.g. Griffin 2005; Hadlock 2005; Kristof 2005; Young 2007). As the articles here presented show, though, the internet is not merely changing Asian societies, but is interacting with local cultures and societal structures across Asia to create

D. K. Herold $(\bowtie)$

Department of Applied Social Sciences,

Hong Kong Polytechnic University,

Kowloon, Hong Kong

e-mail: ssherold@polyu.edu.hk new practices and communities of people sharing facets of their on- and off-line lives.

Before introducing the papers in this issue, though, this brief introduction wants to re-create some of the frame of reference provided by some of the past work done on how Web 2.0 has influenced Asian societies, as well as on how Asian societies have appropriated the internet into their own socio-cultural and political settings. Given that my own research is focused on the Chinese internet, my examples will mainly come from Chinese cyberspace, but attempts have been made to provide examples that apply beyond China to the rest of Asia as well.

\section{Web 2.0 and Asia}

The advent of the interactive communication and content-creation tools collectively referred to as "Web 2.0" emphasized and broadened the interactive features of the internet. Communication on the internet had been largely one-way from the producer of a website to the consumer who accessed it from his/her own computer. This changed with the advent of blogs, social networking sites, online document collaboration services, etc. as these tools worked on the assumption that the provision of information was no longer the main purpose of the internet. Instead, communication and interaction became goals in themselves, and internet users began to collaborate in the creation and collation of information, while 
user created content replaced the consumption of professionally designed content pages.

People who grew up with the new possibilities offered by Web 2.0 came to be labeled "digital natives" (or "Net Gen" or "Google Generation") who were different from the "digital immigrants" of earlier generations, in need of both creative expression, as well as constant interaction with their peers (see e.g. Prensky 2001a, b; Roberts 2005). Even if I do not completely agree with the sharp divide Prensky and others are describing, I would still argue that in very measurable ways, technology has transformed the way people live their lives by requiring (and making possible) previously unprecedented levels of interaction and connectivity.

This immersion into a new technological life-style and its attendant high level of interactivity has farreaching consequences for internet users employing Web 2.0 technologies. Not only are they more interactive than earlier internet users (or non-users), but their interactivity can be seen as an expression of underlying assumptions that could ultimately even influence the political attitudes of the users. Arsène (2008) argues that the continuity of online interactions made possible by Web 2.0 dictates the development of certain minimum standards of flexibility and politeness of internet users. In order to keep interacting, internet users have to be flexible enough to accept conflicting opinions, arguments, and even abuse, while also being polite themselves so as to ensure that other users will willingly read their postings. Arsène regards this minimum standard as a natural development within an interactive community, as individual users have the choice to leave the community and join another one if they are offended by other users.

The continuity of the interactions within the community represents a constant re-negotiation of values, which can be seen as a rudimentary form of public intercourse that in time could grow into the beginnings of a public sphere, and ultimately into a democratic system. While he admits that most Chinese internet users are currently only interested in entertainment, and not in politics, he argues that the intrinsic values of the internet, e.g. politeness, are already beginning to appear in Chinese cyberspace. Despite the primary interest of Chinese users in online entertainment, the increase in so-called Human Flesh Search Engines demonstrates that Chinese "netizens" (internet + citizen) are interested in more than mere entertainment and that they are eager to make their opinions known and to influence events in real life (see e.g. Herold 2008; McLaughlin 2009).

In a similar manner Griffiths (2008) and Kamel Boulos and Wheeler (2007) argue that Web 2.0 is not primarily a technological innovation, but instead a socio-cultural change. Web 2.0 is presented as a revolution of knowledge management and of collaborative practices that enables users to communicate and interact better with each other, which will force businesses and governmental structures to engage users in new ways. Instead of being able to keep their distance, recent developments show that businesses and government officials have had to adopt more interactive approaches in their dealings with people, which demonstrates a logical, and maybe inescapable political change built into the structure and philosophy of Web 2.0 technologies (for examples in China, see Hartford 2005; Zhai and Liu 2007; Tang 2008).

Dan et al. (2009) demonstrate that the internet has even had an impact on how Asian urbanites construct their social networks. According to their research, sociability patterns in Asia have changed from being focused on kin, neighborhood, classmates, etc. to individually selected online communities to which an internet user connects. Though still being a collectivist organization of society, the collectives are no longer based on inherited societal structures and family ties, but are now more flexible, and based on individual choices. This element of individual choice within a communal society is beginning to create new forms of societies and communities within Asian cities and as a result is starting to change the structure and cultural characteristics as well as the political landscapes of Asian societies, as new individual associations and networks built on shared interests produce groups empowered to demand that their interests be respected.

Looking at all of the examples presented here, I would still vehemently argue against any deterministic view of the effects of technology in general, or the internet and Web 2.0 in particular. However, in my opinion the above examples show that the introduction of the internet in Asia has had undeniable effects on local societies. The internet did not simply change Asian societies upon its adoption, though. Instead, local communities across Asia developed their own approaches to the internet, thus influencing the (local) 
internet as much or more as they have been influenced by it.

\section{Asia and Web 2.0}

Asian societies and cultures have proved resilient over the course of history, and China in particular, has repeatedly managed to first subsume and then suppress the influences of non-Chinese invaders, e.g. the Mongols, the Manchus, etc. In part, it could be argued that the collectivist nature of Asian cultures is better at the reinterpretation and re-appropriation of outside influences than the individualist cultures that have developed based on Graeco-Roman traditions. Chau (2008, p. i) argues that collectivist cultures create a need for "value sharing, cooperation, and social responsibility" that is well-met in Web 2.0 technologies, which might explain the eagerness with which Chinese internet users have taken to blogging, bulletin boards (BBS), or even the "Human Flesh Search Engines". In particular the latter, could be seen as an adaptation of Web 2.0 technologies to the needs of a collectivist culture for shared values, coupled with a feeling of social responsibility for those who transgress against the norms and values of their society (see also Zheng and $\mathrm{Wu} 2005$ ).

The collectivist orientation of internet users in Asia has also produced a markedly nationalistic slant to many Asian websites and online communities. This has repeatedly been commented upon by media sources (see e.g. Shen and Zhao 2007; Grossman 2006), in particular during 2008 when the Olympic Games in Beijing attracted the attention of many non-Chinese commentators (Branigan (2008); Drew (2008); Forney (2008); Kennedy (2008); Osnos (2008)—see also Chung Tai Cheng's article in this special issue). Wu (2007) showed how Cybernationalism developed in China out of the marriage between internet technology and a latent nationalism and traditionalism in Chinese culture to produce a uniquely Chinese form of nationalism online, characterized by periodic explosions of nationalistic fervor. This online nationalism, driven by the feelings of a collectivist society, often leads to extreme forms of communications online which in turn have an impact on the politics of offline society (see e.g. clover19862003 2008).

Asian societies are not uniform in their adoption of Web 2.0 practices, though, despite their shared collectivist philosophies. As Deyrich and Ess (2007) show, different Asian cultures are engaging with Web 2.0 products and technologies in different ways reflecting their own socio-cultural and political realities. Different communities employ different cultural elements when interacting with each other online, thus creating new cultural-online-communities which find their own voices and expressions. They point out that these new expressions of cultural communities are not entirely new, though, nor identical across Asian societies, but merely the newest iterations in the continuing tensions between the Global and the Local, and as such as much expressions of specific local communities, as they are consequences of the introduction of a new global(-izing) technology.

The same argument is made based on the observations of ICT uses in South Korea by Choi et al. (2008) who assert that every culture, and even every site within a cultural space has its own uses and rules concerning ICTs. Using data from South Korea, they argue that the development of ICTs in Korea have created a complex new socio-political landscape that incorporates the use of technology into pre-existing social structures, local cultures, and political networks in many different ways, thus creating new social milieus, new public spaces for interaction, and reconceptualizations of existing spaces.

For Chinese society, Weber and $\mathrm{Lu}$ (2007) show how Chinese cultural values are employed to regulate online behavior through a self-disciplining of online actors, while Yang (2003b) argues that it is precisely these Chinese cultural practices that are increasingly serving as points of cultural identification, and empowerment for Chinese living abroad and seeking a connection to their cultural roots. In another article, Yang (2003a) additionally shows how this collective identification online has led to the emergence of a quasi-civil society that is based on both the sociopolitical and cultural structures of Chinese (offline) society and technological advances provided by the internet (see also Tai 2004).

Taking a different approach, but also arguing for a culturally specific interpretation of internet technologies, Li and Kirkup (2007) present comparative data that demonstrates that there are significant differences in the way British and Chinese students approach, understand and use the internet. Their research shows that cultural attitudes both towards gender roles, as 
well as towards technology has a large impact on the adoption and usage patterns of internet technologies. Additionally, they established that Chinese internet users see the internet mostly as a tool for entertainment, rather than a source for information (p. 310). Chinese internet users frequently mention that they are "playing the internet" when they are asked to describe their experiences, but rarely talk about information they have gained through accessing the internet, which might serve to explain why relatively few Chinese access foreign news sites online, contrary to media expectations (see e.g. The Guardian 2005; Ahl et al. 2006; MacKinnon 2008; Mao 2008).

As the studies presented here demonstrate, a localization of internet practices to fit into Asian cultures and contexts has definitely taken place, while it can equally not be denied that the introduction of new technologies in the form of Web 2.0 have had an impact on local cultures and politics. Online society is neither the product of a globalizing technology that erodes local differences, nor is it merely an outgrowth of local practices, customs, and political structures. Instead, communities on the internet create their own online culture that draws on multiple influences to produce unique amalgamations of cultural, political, and technological practices that are constantly redefining the relationship between the local and the global for its users.

\section{The Articles in this Special Issue}

The articles collected for this special issue want to add to the descriptions and conceptualizations of the internet in Asia by providing both additional data, as well as new theoretical frameworks for an appraisal of Asian internet practices and communities. Online communities in Asia (and elsewhere) are constantly re-negotiating their own positions between global technological advances and local socio-political and cultural practices and this is reflected in the papers presented here, which offer different perspectives and understandings for the nexus between the online and the offline world in Asia.

James E. Katz and Chih-Hui Lai argue in their paper that Asian bloggers in particular have had an influence on the production and consumption of news through their reinterpretation of events reported in the mainstream media. Their research suggests that Asian bloggers have become acceptable sources of news to many Asian people. They are perceived as alternative sources providing interpretations of events that often differ from the official versions broadcast by the largely state-controlled or state-influenced mass media of East and Southeast Asia.

Guobin Yang's paper argues against the technological determinism evidenced in many studies of the effects of the internet. Through a re-appropriation of Raymond Williams' work on television, he argues that the use of the internet in China (and in Asia) cannot be traced back solely to inherent characteristics of the internet, but has to be seen as a product of the interplay between local cultural traditions and technological innovation. The internet did not unilaterally change Chinese society. Instead, a new society with new cultural forms emerged online based on both Chinese traditions, as well as innovations brought about through technology.

Larissa Hjorth outlines some of the imaging practices employed by local communities across East and Southeast Asia to show that within this geographic region there are differences between different localities. Even after the arrival of Web 2.0, not all online communities are empowered and empowering communities. In each locality, there are still processes of empowerment and exploitation that shape the ways in which people engage with the internet and how they interact with each other. While some similarities can be found, local online practices are still deeply rooted in local cultures, expressed in user-created contents demonstrating local techno-cultures.

Thammakit Thammo discusses the internet in Thailand and presents the results of his research into people's perceptions of the usefulness of the internet as a public space. While the internet is largely seen as an elitist space by Thai people, the results of his survey show that the internet is already used in many non-elitist ways as a channel of information and communication. He argues that the domination of the mass media by the government has created a need and a desire for alternative sources of information. This development should be encouraged and supported through programs that broaden internet access for the less privileged members of the population.

Jinqiu Zhao's paper focuses on the introduction of internet access in four rural areas in China. Her research sought to measure the effect an introduction of the internet would have on a rural community. Her 
data shows that there were no universal effects to the process, and that local conditions, as well as local agents played a decisive role in how the internet was received and used. Local needs determined internet usage, and decisions by and positionality of the change agents promoting the internet determined the level of interest and the life-span of local interest. Perceptions of information needs varied from area to area and influenced decisions about internet usage and the inclination of local people to engage with the online information sources.

Chung Tai Cheng presents a case study on one of the nationalistic incidents in China during 2008. Using the call for a boycott of the French supermarket chain Carrefour in China as an example, he discusses the effects the internet has had on the interactions between Chinese people. He argues that Chinese people have incorporated the internet into their offline lives, and that their reception of the internet is based on pre-existing socio-cultural values. His data shows how the internet provides an illusion of truth to Chinese internet users and that this truth then influences their real-life decision making processes.

\section{References}

Ahl, A., Falksohn, R., Klussmann, U., Kremb, J., \& Lorenz, A. (2006, November 29). From China to Iran, web diarists are challenging censors. In: Spiegel Online. Available via http://www.spiegel.de/international/spiegel/0,1518, druck450228,00.html. Accessed 19 February 2009.

Arsène, S. (2008). Web 2.0 in China. The collaborative development of specific norms for individual expression. Paper presented at Politics: Web 2.0: An International Conference, Royal Holloway, London, United Kingdom.

Branigan, T. (2008, March 23). Western stance infuriates young Chinese fed on government propaganda. The Observer. Available via http:/www.guardian.co.uk/world/2008/mar/ 23/tibet.china. Accessed 19 February 2009.

Chau, P. (2008). Cultural differences in diffusion, adoption, and infusion of Web 2.0. Journal of Global Information Management, 16, i-iii.

Choi, J., Foth, M., \& Hearn, G. (2008). Site specific mobility and connection in Korea: Bangs in between public and private. Author manuscript. Accessible via http://eprints. qut.edu.au. Accessed 19 February 2009.

Clover19862003. (2008, April 17). 2008! China Stand Up! In: YouTube. Available via http://www.youtube.com/watch? $\mathrm{v}=$ MSTYhYkASsA. Accessed 19 February 2009.

Dan, S., Doulet, J. -F., \& Keane, M. (2009). Urban informatics in China: Exploring the emergence of the Chinese City 2.0. In M. Foth (Ed.), Handbook of research on urban informatics: The practice and promise of the real-time city (pp. 379-389). Hershey, PA: IGI Global. Accessible via http://eprints.qut.edu.au. Accessed 19 February 2009.

Deyrich, M.-C., \& Ess, C. (2007). Cultural diversity and participatory evolution in IS: Global vs. local issues. In ACIS (Ed.), 18th Australasian Conference on Information Systems-Conference Proceedings (pp. 1035-1045).

Drew, J. (2008, March 24). Protests May Only Harden Chinese Line. Washington Post. Available via http://www.wash ingtonpost.com/wp-dyn/content/article/2008/03/23/ AR2008032301595_pf.html. Accessed 19 February 2009.

Forney, M. (2008, April 13). China's Loyal Youth. The New York Times. Available via http://www.nytimes.com/2008/ 04/13/opinion/13forney.html. Accessed 19 February 2009.

Griffin, P. (2005, June 10). China's internet censorship stranglehold can't last. In: The New Zealand Herald. Available via http://www.nzherald.co.nz/technology/news/ article.cfm?c_id=5\&objectid=10329896. Accessed 19 February $200 \overline{\overline{9}}$.

Griffiths, J. (2008). Web 2.0 is not about technology: it's about human relationships. Market Leader 2008 (Spring), pp. 41-45.

Grossman, L. (2006, February 5). Google under the gun. Time. Available via http://www.time.com/time/magazine/article/ 0,9171,1156598-1,00.html. Accessed 19 February 2009.

Hadlock, C. (2005, September 26). China clamps down on Internet news. In: NBC News. Available via http://www. msnbc.msn.com/id/9489510. Accessed 19 February 2009.

Hartford, K. (2005). Dear Mayor: Online communications with local governments in Hangzhou and Nanjing. China Information XIX, 2, 217-260.

Herold, D. K. (2008). Development of a civic society online? Internet vigilantism and state control in Chinese cyberspace. Asia Journal of Global Studies, 21, 26-37.

Kamel Boulos, M., \& Wheeler, S. (2007). The emerging Web 2.0 social software: an enabling suite of sociable technologies in health and health care education. Health Information and Libraries Journal, 24, pp. 2-23.

Kennedy, J. (2008, March 24). China: Bloggers declare war on Western media's Tibet coverage. Global Voices Online. Available via http://globalvoicesonline.org/2008/03/24/ china-bloggers-declare-war-on-western-medias-tibet-cov erage/. Accessed 19 February 2009.

Kristof, N. (2005, May 24). Death by a Thousand Blogs. In: The New York Times. Available via http://www.nytimes. com/2005/05/24/opinion/24kristoff.html. Accessed 19 February 2009.

Li, N., \& Kirkup, G. (2007). Gender and cultural differences in Internet use: A study of China and the UK. Computers \& Education, 48, pp. 301-317.

MacKinnon, R. (2008). Flatter world and thicker walls? Blogs, censorship and civic discourse in China. Public Choice, 134, 31-46.

Mao, I. (2008, August 5). China's first blogger Isaac Mao: It was just like a fairy story. In: The Guardian. Available via http://www.guardian.co.uk/technology/2008/aug/05/blogging. digitalmedia ?gusrc $=$ rss\&feed $=$ media. Accessed 19 February 2009

McLaughlin, R. (2009, January 28). Human flesh search engines-crowd-sourcing "justice”. In CNET Asia Blogs: The Tech Dynasty. Available via http://asia.cnet.com/ 
blogs/thetechdynasty/post.htm?id=63008617. Accessed 19 February 2009.

Osnos, E. (2008, July 28). Letter from China: Angry Youth. The New Yorker Online. Available via http://www.new yorker.com/reporting/2008/07/28/080728fa fact osnos/. Accessed 19 February 2009.

Prensky, M. (2001a). Digital natives, digital immigrants. On the Horizon, 95, 1-6.

Prensky, M. (2001b). Digital natives, digital immigrants, part II: Do they really think differently. On the Horizon, 96, 1-6.

Roberts, G. (2005). Technology and learning expectations of the net generation. In D. Oblinger, J. Oblinger (Eds.), Educating the net generation (pp. 3.1-3.7). Boulder, Washington D.C.: Educause.

Shen, S., \& Zhao, Y. (2007, January 18). Starbucks faces imperial eviction in China. In: International Herald Tribune. Available via http://www.iht.com/articles/2007/01/18/bloomberg/ sxstarbucks.php. Accessed 19 February 2009.

Tai, Z. (2004). Civil society and internet revolutions. PhD thesis. University of Minnesota, Minneapolis.

Tang, B. (2008, July 10). Classmate Yang goes online: Chinese officials engage netizens. In: Fool's Mountain: Blogging for China. Available via http://blog.foolsmountain.com/ 2008/07/10/classmate-yang-online-officials-engage-neti zens/. Accessed 19 February 2009.
The Guardian. (2005, June 17). The limits of censorship-The web in China. Available via http://www.guardian.co.uk/ technology/2005/jun/17/china.guardianleaders. Accessed 19 February 2009.

Weber, I., \& Lu, J. (2007). Internet and self-regulation in China: The cultural logic of controlled commodification. Media, Culture \& Society, 295, 772-789.

$\mathrm{Wu}, \mathrm{X}$. (2007). Chinese cyber nationalism: Evolution, characteristics, and implications. Lanham: Lexington Books.

Yang, G. (2003a). The co-evolution of the internet and civil society in China. Asian Survey, 433, 405-422.

Yang, G. (2003b). The Internet and the rise of a transnational Chinese cultural sphere. Media, Culture \& Society, 25, 469-490.

Young, M. (2007, May 16). Asia's battle against the Web. In: Asia Times Online. Available via http://www.atimes.com/atimes/ asian_economy/ie16dk01.html. Accessed 19 February 2009.

Zhai, D., \& Liu, C. (2007). Web 2.0 applications in China. In W. Wang (Ed), Integration and Innovation: Orient to E-Society. IFIP International Federation for Information Processing, Volume 252, Volume 2, Springer, Boston, pp. 26-33.

Zheng, Y., \& Wu, G. (2005). Information technology, public space, and collective action in China. Comparative Political Studies, 385, 507-536. 